\title{
APLIKASI PEMAHAMAN LINTAS BUDAYA (CROSSCULTURAL UNDERSTANDING) DALAM PEMBELAJARAN SPEAKING UNTUK MENGATASI KECEMASAN BERBICARA (SPEAKING ANXIETY) PADA MAHASISWA SEMESTER 2 PROGRAM STUDI BAHASA INGGRIS STKIP SILIWANGI
}

\author{
${ }^{1}$ Anita Anggraeni, ${ }^{2}$ Cynantia Rachmijati \\ ${ }^{1,2}$ STKIP Siliwangi Bandung
}

\begin{abstract}
ABSTRAK
Pemahaman lintas budaya (Cross Cultural Understanding) adalah mata kuliah yang mempelajari tentang keragaman budaya yang ada di dunia sekaligus dampak budaya tersebut terhadap kelangsungan masyarakat sosial dalam lingkup budaya tertentu. Program Studi Pendidikan Bahasa Inggris STKIP Siliwangi menjadikan CCU sebagai salah satu matakuliah wajib bagi mahasiwa. Matakuliah ini bertujuan membekali mahasiswa STKIP pengetahuan cara berkomunikasi dan berinteraksi dengan latar belakang budaya dimana bahasa inggris menjadi bahasa pengantar utamaanya. Namun kenyataannya banyak mahasiswa yang masih kesulitan dalam berkomunikasi menggunakan bahasa Inggris. Hal ini dinamakan "speaking anxiety". Para mahasiswa STKIP Siliwangi yang kini berada di semester 2 dapat dikategorikan sebagai generasi $\mathrm{Z}$ tidak terlepas dari menyukai kebudayaan popular tersebut sehingga menjadi penggemar hingga menjadi identitas mereka. Selain kebudayaan western, muncul pula kebudayaan-kebuadayaan besar lainnya belakangan ini, misalnya kebudayaan Jepang, dan Korea. Timbullah istilah-istilah seperti otaku (penggemar anime kebudayaan Jepang), k-popper ( penggemar music kebudayaan Korea Selatan), penyuka drama Thailand dan lain sebagainya. Dengan cross cultural knowledge diharapkan mahasiswa akan lebih percaya diri dalam berbicara dan mereduksi kecemasan berbicara (speaking anxiety). Metode penelitian ini adalah metode penelitian deskriptif kualitatif. Data dalam penelitian ini didapat dari hasil wawancara dan questionnaire yang diadaptasi dari "Language Classroom Anxiety Scale (FLCAS)" karya Horwitz dan "Value Rubric Intercultural Knowledge" karya Oregon State University. Ditemukan bahwa penyebab speaking anxiety adalah $79 \%$ faktor internal, $85 \%$ kurang pengetahuan dan $30 \%$ faktor dosen dan teman. Hasil penelitian menemukan bahwa keterkaitan antara pemahaman kebudayaan erat kaitannya dengan menurunnya tingkat kecemasan mahasiswa dalam berbicara bahasa inggris dan perlunya strategi penerapan cross cultural understanding untuk meningkatkan pemahaman kebudayaan sehingga bisa membantu mengurangi kecemasan berbicara.
\end{abstract}

Kata kunci :cross cultural understanding, speaking, anxiety 


\section{PENDAHULUAN}

\section{A.Latar Belakang}

Globalisasi membawa dampak yang cukup besar bagi perubahan zaman. Selain menjadikan kemampuan berbahasa Inggris menjadi standar percakapan namun juga menjadikan internet sebagai salah satu media yang paling banyak digunakan untuk memperoleh informasi. Bahasa Inggris diajarkan di negara Indonesia dari tingkat SD hingga perguruan tinggi. Sebagai bahasa asing yang cukup banyak digunakan di Indonesia, mereka yang memiliki kemampuan berbahasa Inggris yang cukup baik bisa memiliki potensi akan lebih unggul dalam memperoleh pekerjaan ataupun memperoleh beasiswa. Sehingga 4 language skills bahasa Inggris ini yaitu speaking, reading, listening dan writing akan baik bila dikuasai oleh mahasiswa. Terutama, kemampuan speaking. Mahasiswa Pendidikan Bahasa Inggris STKIP Siliwangi harus menggunakan bahasa Inggris dalam kehidupan akademis mereka sehari-hari. Menggunakan buku-buku berbahasa Inggris, mengerjakan tugas-tugas dalam berbahasa Inggris dan bahkan berkomunikasi dan presentasi dalam bahasa Inggris. Namun, banyak juga dari mereka yang masih kesulitan dalam berkomunikasi menggunakan bahasa Inggris. Umumnya mereka merasa gugup dan cemas saat harus berkomunikasi dalam berbahasa Inggris. Karena berbagai alasan antara lain cemas, takut, malu dan lain sebagainya. Hal ini dinamakan "speaking anxiety".

"Anxiety is the subjective feeling of tensio n, apprehension, nervousness, and worry associated with an arousal of the autonomi $c$ nervous system.Anxiety has been found to interfere with many types of learning an $d$ it is only logical that this would also apply to second language learning "(Horwitz, 2001)

Horwitz berpendapat bahwa kecemasan ini adalah perasaan tegang, gugup, cemas dan khawatir yang terkait sistem saraf dan bisa mengganggu pelajar yang mencoba mempelajari bahasa asing.
Pengajaran Bahasa Asing (L2) terkait dengan masalah standards (ACTFL/ American Council on the Teaching of Foreign Languages , 2004).

Standards for Foreign Language

\section{Learning}

berupa $5 \mathrm{C}$ yaitu:

1) Communication, yaitu berupa komunikasi Cultures, yaitu pengetahuan dan pemahaman budaya

2) Connections, yaitu keterkaitan antara budaya dan bahasa yang dipelajari

3) Comparisons, yaitu membandingkan budaya sendiri dengan budaya asing

4) Communities, yaitu elemen 1 hingga 4 yang menjadikan pelajar memiliki

5) pemahaman dan sudut pandang yang luas mengenai budaya dan bahasa

Dari tahun ke tahun, kebudayaan asing banyak mendatangkan pengaruh di Indonesia. Umumnya dimulai dari acara tv, film, musik dan lainnya. Sehingga kebudayaan-kebudayaan asing tersebut menyebar, umumnya para generasi $\mathrm{Z}$ tersebut menyukai kebudayaan tersebut sehingga menjadi penggemar hingga menjadi identitas mereka. Timbullah istilah-istilah seperti otaku (penggemar anime kebudayaan Jepang), k-popper ( penggemar music kebudayaan Korea Selatan), penyuka drama Thailand dan lain sebagainya.

Hal ini sedikit banyak berpengaruh pada kemampuan berkomunikasi para mahasiswa STKIP Siliwangi, khususnya mahasiswa Program Studi Pendidikan Bahasa Inggris. Hidup dalam dunia yang sangat global dengan kebudayaan yang beragam, maka para pembelajar bahasa perlu untuk mengembangkan kemampuan berbahasanya namun juga kemampuan berbudayanya agar bisa berinteraksi dengan orang lain dari berbagai latar belakang kebudayaan. Hal tersebut dinamakan komunikasi antar budaya atau cross cultural understanding. Karena itu pengetahuan terkait ilmu pengetahuan komunikasi antar budaya sebaiknya 
diajarkan kepada para pembelajar, demikian juga dengan kebudayaannya. Dengan pemahaman yang lebih baik , maka kemampuan berkomunikasi siswa juga akan lebih baik. (Ahmad, 2003).

\section{B.Tujuan Penelitian}

Tujuan dari penelitian ini adalah : Maksud dari diadakannya penelitian ini adalah untuk memperoleh data empiris mengenai hubungan antara pemahaman lintas budaya (cross cultural) sebagai cara untuk mengatasi kecemasan berbicara (speaking anxiety). Sehingga diharapkan, penelitian ini bertujuan untuk mendapatkan gambaran mengenai hubungan antara cross cultural competence dengan speaking anxiety pada mahasiswa STKIP Siliwangi Jurusan Pendidikan Bahasa Inggris.

\section{Ruang lingkup penelitian}

Ruang lingkup penelitian ini adalah sebagai berikut:

1) Subyek penelitian adalah mahasiswa STKIP Siliwangi angkatan 2016 Jurusan Pendidikan Bahasa Inggris

2) Komponen yang menjadi aspek penelitian adalah kecemasan berbicara, penyebab kecemasan berbicara, pemahaman mengenai lintas budaya terutama dalam hal ini adalah fenomena budaya popular serta strategi untuk mengatasi kecemasan berbicara melalui pemahaman lintas budaya popular.

\section{KAJIAN TEORI}

\section{A. Budaya}

Budaya dapat dilihat sebagai suatu perilaku, nilai-nilai, sikap hidup, dan cara hidup untuk melakukan penyesuaian dengan lingkungan, dan sekaligus cara untuk memandang persoalan dan memecahkannya. Kebudayaan juga didefinisikan sebagai keseluruhan sistem gagasan, tindakan dan hasil karya manusia dalam rangka kehidupan masyarakat yang dijadikan milik diri manusia dengan cara belajar (Koentjaraningrat, 2003).

Dalam bahasa Inggris, kebudayaan disebut culture yang berasal dari bahasa
Latin colere yang berarti mengolah atau mengerjakan. The American Herritage Dictionary mengartikan culture sebagai suatu keseluruhan dari pola perilaku yang ditransmisikan melalui kehidupan sosial, seni, agama, kelembagaan dan semua hasil kerja dan pemikiran manusia dari suatu kelompok manusia.

\section{B. Kecemasan Berbahasa Asing (Foreign Language Anxiety)}

Horwitz and Cope (1986)

mengemukakan bahwa kecemasan berbahasa asing atau foreign language anxiety (FLA) merupakan kecemasan wajar yang mirip dengan kecemasan berbicara di depan umum atau public speaking anxiety. Banyak orang yang mengalami kecemasan pada beberapa situasi. Salah satunya adalah kecemasan pada saat berbicara di depan umum dengan menggunakan bahasa asing (bukan bahasa asli).

Faktor-faktor penyebabnya adalah self perception (persepsi diri) dan cultural differences (perbedaan kebudayaan).Orang dengan self-esteem yang rendah cenderung khawatir dengan apa yang akan orang lain katakanatentang dirinya. Perbedaan kebudayaan juga terkadang membuat kita merasa terbatas, karena membuat kita melakukan sesuatu dengan cara yang berbeda dan bahkan mungkin membuat kita merasa tidak nyaman jika belum terbiasa dengan perbedaan tersebut.

\section{Kecemasan Berbicara (Speaking Anxiety) \\ Menurut Spielberger (1983)}

kecemasan atau anxiety is the subjective feeling of tension, apprehension, nervousness and worry associated with an arousal of the automatic nervous system atau kecemasan adalah perasaan subjektif dari ketegangan, ketakutan, kegelisahan dan khawatir berkaitan dengan gairah dari system saraf otomatis.

Jones (2004) menunjukkan bahwa banyak orang merasa takut berbuat salah 
(melafalkan kalimat dengan salah) dan takut akan menjadi bahan cemoohan teman-teman yang melihat mereka berbicara dengan bahasa kedua seperti bahasa Inggris, karena belum sepenuhnya menguasai karena "takut terlihat aneh, bodoh, tidak berkompeten di mata penonton". Sebagai hasilnya karena perasaan takut dan khawatir tersebut banyak orang mengatakan bahwa belajar bahasa asing / bahasa kedua selalu menjadi masalah, karena banyak orang yang memperhatikan, mengkritik, menertawai dan bahkan disalahkan.

Meskipun kecemasan merupakan perintang yang besar bagi siswa, tapi Oxford (1994) mengatakan bahwa speaking dan presentasi di depan kelas sebagai aktivitas yang paling memproduksi kecemasan. Tetapi ternyata writing, reading, listening juga menciptakan ketakutan tergantung dari siswanya. Berikut ini adalah tanda dari kecemasan berbahasa (Oxford, 1994) :

1) General avoidance (pengabaian secara umum) misalnya "melupakan “ jawaban, menunjukkan kecerobohan, memotong kelas, datang terlambar, datang tanpa persiapan apa-apa, menghasilkan produksi verbal yang rendah, kurang berpartisipasi di kelas, menunjukkan ketidakmampuan untuk menjawab meskipun pertanyaan yang sangat sederhana.

2) Physical actions (tindakan fisik), misalnya menggeliat-liat, gelisah/ tidak tenang, memainkan rambut atau baju, menyentuh benda secara gelisah, gagap, menunjukkan tingkah laku yang gugup, tidak mampu menghasilkan bunyi atau intonasi dari bahasa target meski diulang berkali-kali.

3) Physical symtopms (gejala fisik), mengeluh sakit kepala, pegal-pegal, merasakan sakit atau tegang yang tidak dapat dijelaskan.

Oleh karena itu, pengaruh kecemasan terhadap proses pembelajaran menjadi salah satu indicator sukses atau tidaknya seseorang bisa mempelajari bahasa tersebut.

\section{Pemahaman Lintas Berbudaya (Cross Cultural Understanding) \\ Cross cultural understanding has} been defined by Finney \& Orr as the interpersonal understanding of the culture and experiences between people of different cultures (1995). Crosscultural understanding, in turn, can be separated into three major components: critical understanding, empathetic understanding, and conceptual understanding of another (Louie, 2006). Cross-cultural understanding, then, can be seen as a complex process involving several higherorder thinking skills.

Menurut Finney dan Orr, cross cultural understanding adalah pemahaman dan pengalaman saling berbagi kebudayaan antara mereka yang berbeda kebudayaan. Terdiri atas 3 komponen yaitu : pemahaman kritis, pengertian empati dan pemahaman mengenai konsep lintas budaya itu sendiri. Gabungan ketiga hal tersebut menggambarkan kompleksitas pemahaman dari lintas budaya tersebut.

Tujuan kita memahami tentang lintas budaya adalah :

1) Dapat berkomunikasi dengan baik dengan manusia yang berbeda kebudayaan

2) Dapat memperdalam pengalaman atau pengetahuan

3) Dapat membuat kita lebih peka dengan budaya sendiri

4) Dapat membantu memahami ketika ada kontak antar budaya

5) Dapat terlibat dengan budaya lain agar menciptakan hubungan yang langgeng

\section{METODE PENELITIAN}

Metode penelitian ini adalah metode penelitian deskriptif kualitatif. Penelitian kualitatif ini terfokus pada penelitian tentang perilaku dan tindaktanduk siswa, yang dalam penelitian ini terpusat pada mengapa siswa mengalami kecemasan berbicara serta melihat pengaruh dari aplikasi pemahaman lintas budaya untuk mengatasinya (Nunan, 1992). 


\begin{abstract}
Pendekatan kualitatif diharapkan mampu menghasilkan uraian yang mendalam tentang ucapan, tulisan, dan atau perilaku yang dapat diamati dari suatu individu, kelompok, masyarakat, dan atau organisasi tertentu dalam suatu setting konteks tertentu yang dikaji dari sudut pandang yang utuh, komprehensif, dan holistik.
\end{abstract}

Penelitian ini merupakan penelitian korelasional yang akan melihat hubungan antara dua variable yaitu pemahaman lintas budaya dan speaking anxiety.
1) Variabel 1 yaitu pemahaman lintasbudaya
2) Variabel 2 yaitu kecemasan berbicara

Alat ukur atau instrument dalam penelitian ini adalah kuesioner sejumlah 30 soal yang diadaptasi dari "Value Rubric Intercultural Knowledge" dan "Foreign Language Class Anxiety" dengan skala SST (Sangat Setuju), S (Setuju), N (Netral), TS (Tidak Setuju) dan STS (Sangat Tidak Setuju).

Populasi dalam penelitian ini adalah mahasiswa angkatan 2016 Jurusan Pendidikan Bahasa Inggris kelas regular sejumlah 164 mahasiswa. Sementara sample pada penelitian ini adalah 9 mahasiswa untuk diwawancarai serta 3 orang guru kursus bahasa Inggris.

\section{HASIL DAN PEMBAHASAN}

Dari data kuesioner maka bisa dilihat bahwa $79 \%$ mahasiswa merasa bahwa penyebab kecemasan berasal dari dirinya yang merasa tidak memiliki dasar yang kuat dalam berbicara dalam bahasa inggris. Kecemasan itu ditandai dengan timbulnya rasa gugup, malu, takut ditertawakan, bingung, tidak mampu berkata-kata, berkeringat dingin dan tidak konsentrasi. Frekuensi mahasiswa yang menjawab bahwa hal-hal tersebut terjadi pada dirinya adalah $75 \%$. Sebagian besar responden $(85 \%)$ menjawab kecemasan tersebut terjadi karena kurangnya dasar pengetahuan yang didapat dari bangku sekolah terdahulu berkaitan dengan bahasa inggris. Terutama kebiasaan berbicara jarang sekali mendapat kesempatan untuk berbicarasaat di Sekolah Menengah Atas.

$30 \%$ diantara responden mengatakan bahwa kecemasan mereka dalam berbicara disebabkan oleh faktor dosen yang tegas, dan melihat temanteman yang berkemampuan lebih tinggi dari dirinya sehingga membuat dirinya merasa tidak percaya diri saat berbicara walaupun keinginan untuk berbicara tinggi. Sebagian besar responden berusaha mengatasi kecemasan tersebut dengan berbagai macam cara yaitu, $51 \%$ berlatih dengan teman, $53 \%$ memaksakan diri untuk berbicara, $34 \%$ mengambil kursus bahasa inggris di luar.

Maka dari pemaparan tersebut tampak jelas bahwa faktor terbesar penyebab kecemasan berbicara adalah kurangnya pengetahuan dalam berbicara dalam bahasa Inggris yang diikuti dengan faktor internal. Sementara pilihan utama untuk mengatasi kecemasan berbicara adalah berlatih dengan teman karena dianggap sebagai pilihan yang paling mudah dan bisa sharing sehingga mengurangi kecemasan tersebut.

Selain menyebarkan kuesioner, pada penelitian ini dilakukan pula wawancara mendalam (indepth interview) dengan 9 orang responden. Hasil wawancara menguatkan hasil kuesioner yang didapat. Responeden menerangkan bahwa kemampuan bahasa inggris mereka tidak terlampau baik karena Dasar kemampuan bahasa inggris yang kurang semenjak bangku SMA. Rasa tidak suka pada bahasa inggris karena aturan yang dirasa berbeda jauh dengan bahasa ibu mereka yaitu bahasa Indonesia. Keterpaksaan mempelajari bahasa inggris karena telah masuk prodi bahasa inggris, yang dilakukan karena anjuran orang tua atau kakak.

Dari hasil wawancara peneliti menemukan bahwa rasa cemas pada yang paling dominan dirasakan saat mahasiswa harus mengemukakan opininya baik tentang hal yang berkaitan dengan dirinya maupun orang lain. Responden mengatakan bahwa kosakata dan grammar yang 
diajarkan oleh guru di SMA sama sekali tidak mereka mengerti karena terkadang terlalu cepat, dan susah dimengerti karena siswa kurang mendapatkan brainstorming dan dorongan emosional saat belajar. Responden kurang mengerti hubungannya belajar bahasa Inggris dengan keuntungan yang akan diperoleh di kehidupan nyata. Mereka juga mengemukakan bahwa kegiatan berbicara bahasa Inggris yang paling susah untuk diikuti, dibandingkan dengan kegiatan membaca, mendengarkan ataupun menulis berbahasa Inggris. Ini disebabkan karena dalam berbicara, mereka dituntut untuk merespon dengan langsung, tepat dan berterima, sedangkan kemampuan mereka untuk memilih kosa kata yang tepat dan memakai grammar yang benar masih kurang . Keterkaitan antara materi bahasa inggris yang diajarkan dan penggunaannya dalam keseharian baru mereka sadari keterkaitannya saat mereka telah menjadi mahasiswa pada program studi bahasa inggris.

Situasi di kelas kini terkadang kurang kondusif, diakibatkan oleh mereka yang terkadang lambat untuk mengikuti jalannya proses pembelajaran, dan mereka yang cepat menerima pelajaran. Karena jumlah mahasiswa dalam satu kelas yang relatif besar. Ditambah lagi, mahasiswa lebih dominan menggunakan bahasa daerah dan bahasa Indonesia. Akibat dari kurangnya penggunaan bahasa Inggris ini, mahasiswa jadi kurang terlatih untuk melafalkan kosakata bahasa Inggris, diluar dari penggunaan grammar. Selain itu rasa cemas muncul ketika seseorang harus berbicara ataupun berinteraksi dengan orang lain. Rasa cemas itu muncul sebelum, selama dan setelah proses kegiatan berbicara itu berlangsung. Ini kemudian mempengaruhi kelancaran mereka berbicara, sehingga mereka cenderung berbicara berputar-putar dan tidak jelas arahnya. Rasa cemas inilah yang kemudian menimbulkan perasaan tertekan yang membuat mereka ragu mereka akan berhasil menyampaikan maksud mereka dengan jelas. Ini menyebabkan siswa dengan kemampuan berbicara bahasa Inggris rendah ini semakin cemas dan tertekan karena merasa selalu tertinggal dan kurang mampu mengikuti perkuliahan.

Kesembilan responden saat diwawancarai juga mengungkapkan bahwa mereka sejak SMP memiliki kebiasaan menonton film dan mendengarkan lagu berbahasa inggris. Namun kebiasaan ini hanya terbatas pada mendengarkan irama lagu yang menarik dan cerita film yang menarik saja. Tanpa memahami makna dan arti dari apa yang didengar dan ditontonnya. Enam responden mengatakan bahwa kecemasan dalam berbicara bahasa inggris berkurang setelah mereka mengetahui dan mengerti kebiasaan dan kebudayaan barat yang dipelajari saat perkuliahan berlangsung. Mereka mengatakan hal tersebut serupa dengan apa yang mereka rasakan dengan kebiasaan dan ketertarikan terhadap bahasa Korea dan Jepang. Pemahaman dan kesukaan terhadap kebudayaan Korea dan Jepang membuat mereka memiliki kepercayaan diri lebih tinggi saat harus berbicara dalam bahasa tersebut. Hal tersebut kini mereka rasakan pada bahasa Inggris. Pemahaman terhadap 
kebudayaan barat membuat mahasiswa merasa lebih dekat dan mengerti pola berpikir dan gaya berbicara barat.

Untuk strategi pembelajaran speaking dan aplikasi cross cultural understanding, peneliti mencoba mengaplikasikannya dalam tahapan berikut ini :

\begin{tabular}{|c|c|c|c|}
\hline $\begin{array}{l}\mathbf{N} \\
\mathbf{0}\end{array}$ & Tahapan & Pengertian & Tindakan \\
\hline 1 & \begin{tabular}{|l|} 
Cross \\
Cultural \\
Awareness
\end{tabular} & $\begin{array}{l}\text { Berkemban } \\
\mathrm{g} \text { dari } \\
\text { pengetahuan } \\
\text { lintas } \\
\text { budaya kala } \\
\text { pembelajar } \\
\text { memahami } \\
\text { dan } \\
\text { mengapresia } \\
\text { si secara } \\
\text { internal } \\
\text { suatu } \\
\text { budaya }\end{array}$ & $\begin{array}{l}\text { Pemutaran } \\
\text { film } \\
\text { berbahasa } \\
\text { Inggris } \\
\text { tanpa } \\
\text { disertai text } \\
\text { terjemahan }\end{array}$ \\
\hline 2 & \begin{tabular}{|l|} 
Cross \\
Cultural \\
Sensitivity
\end{tabular} & $\begin{array}{l}\text { merujuk } \\
\text { kepada } \\
\text { kemampuan } \\
\text { untuk } \\
\text { membaca } \\
\text { situasi, } \\
\text { konteks, dan } \\
\text { perilaku } \\
\text { yang secara } \\
\text { budaya } \\
\text { berakar dan } \\
\text { dapat } \\
\text { bereaksi } \\
\text { kepadanya } \\
\text { dengan tepat }\end{array}$ & $\begin{array}{l}\text { Menerjema } \\
\text { hkan } \\
\text { beberapa } \\
\text { puisi } \\
\text { berbahasa } \\
\text { Inggris } \\
\text { yang } \\
\text { bertemakan } \\
\text { budaya }\end{array}$ \\
\hline 3 & $\begin{array}{l}\text { Cross } \\
\text { Cultural } \\
\text { Competen } \\
\text { ce }\end{array}$ & $\begin{array}{l}\text { Kompetensi } \\
\text { lintas } \\
\text { budaya } \\
\text { melampaui } \\
\text { pengetahuan } \\
\text {, kesadaran } \\
\text { dan } \\
\text { kepekaan } \\
\text { karena ia } \\
\text { merupakan } \\
\text { pencernaan, } \\
\text { per-paduan }\end{array}$ & $\begin{array}{l}\text { Mendengar } \\
\text { kan lagu } \\
\text { lagu } \\
\text { berbahasa } \\
\text { Inggris dan } \\
\text { menerjema } \\
\text { hkannya }\end{array}$ \\
\hline
\end{tabular}

\begin{tabular}{|c|c|c|c|}
\hline & & $\begin{array}{l}\text { dan } \\
\text { transformasi } \\
\text { dari semua } \\
\text { keterampila } \\
\mathrm{n} \text { dan } \\
\text { informasi } \\
\text { yang dicari, } \\
\text { diterapkan } \\
\text { untuk } \\
\text { menciptaka } \\
\text { n sinergi } \\
\text { budaya di } \\
\text { tempat kerja }\end{array}$ & \\
\hline 4 & \begin{tabular}{|l|} 
Cross \\
cultural \\
understan \\
ding
\end{tabular} & $\begin{array}{l}\text { merujuk } \\
\text { kepada } \\
\text { pengenalan } \\
\text { tingkat } \\
\text { permukaan } \\
\text { dengan } \\
\text { karakteristik } \\
\text { budaya, } \\
\text { nilai, } \\
\text { kepercayaan } \\
\text { perilaku. dan }\end{array}$ & $\begin{array}{l}\text { Membahas } \\
\text { berbagai } \\
\text { kebiasaan } \\
\text { unik pada } \\
\text { budaya } \\
\text { bahasa } \\
\text { Inggris }\end{array}$ \\
\hline
\end{tabular}

Bisa disimpulkan bahwa dari hasil kuesioner serta wawancara ini bahwa faktor terbesar kecemasan berbicara (speaking anxiety) adalah faktor internal dari diri sendiri. Dimana mahasiswa menjadi gugup, cemas, malu dan takut untuk mulai berkomunikasi dan menggunakan bahasa Inggris karena merasa takut serta masih rendahnya kemampuan berbahasa. Untuk pemahaman lintas berbudaya (cross cultural understanding) umumnya mereka menyukai kebudayaan Barat,Jepang dan Korea namun masih dari segi film dan lagu saja. Dari segi pemahaman kebudayaan, pola hidup dan pola pikir masih tidak terlalu dipahami namun cukup banyak memberikan pengaruh sehingga mereka merasa lebih percaya diri dan mencoba berkomunikasi dalam bahasa-bahasa asing tersebut dan terutama dalam bahasa Inggris. 


\section{KESIMPULAN}

Berdasarkan hasil analisa data dan pembahasan diatas, dapat disimpulkan bahwa terdapat pengaruh kontribusi antara kecemasan diri yang dialami mahasiswa dengan kemampuan berbicara bahasa Inggris. Dari hasil kuesioner, dapat terlihat bahwa ini tergolong pengaruh yang kuat. Adapun faktor-faktor yang mempengaruhi tingkat kecemasan diri mereka dalam berbicara bahasa Inggris adalah kecemasan diri dalam berkomunikasi bahasa Inggris dan ketakutan akan penilaian negatif dari orang lain. Faktor- faktor bisa dinetralisir dengan memberikan pemahaman tentang kebudayaan barat bahkan kebudayaan Jepang dan Korea yang digemari oleh mahasiswa sehingga menimbulkan rasa nyaman pada mahasiswa ketika mengikuti proses perkuliahan Dari uraian diatas maka terlihat bahwa keterkaitan antara pemahaman kebudayaan erat kaitannya dengan menurunnya tingkat kecemasan mahasiswa dalam berbicara bahasa inggris dan perlunya strategi penerapan cross cultural understanding untuk meningkatkan pemahaman kebudayaan sehingga bisa membantu mengurangi kecemasan dalam berbicara.

\section{DAFTAR PUSTAKA}

Amila,Putri.(2013).’Pengaruh kecemasan berbahasa asing terhadap performa berbicara di depan umum menggunakan bahasa Inggris sebagai bahsa kedua". Semarang : Universitas Negeri Semarang

Edin,Ahmad Abel.(2014)."Teaching culture in the classroom to Arabic language students". International Education Studies Vol 8 No 2 2015. ISSN 19139020

Hansel,Bettina.(2008)."Looking at intercultural sensitivity, anxiety and experience with other cultures". AFS Impact Study.

Horwitz,Elain.(1986)."Foreign language classroom anxiety".The Modern
Language Journal, Vol. 70, No. 2 (Summer, 1986), pp. 125-132

Mahmudah,Inayatul.(2015).’Dampak

budaya Korean Pop terhadap penggemar dalam perspektif keberfungsian sosial". Yogyakarta : Universitas Islam Negeri Sunan Kalijaga

Ochipinti,Alessia.(2009)."Foreign language anxiety in class speaking activities".The University of Oslo. Unpublished paper.

Oktaviani,Fatmala Sari.(2013)."An analysis of students English language anxiety at SMAN 7Padang”. Journal of EnglishLanguage Teaching. Vol 1 no 3 Juni 2013 Universitas Negeri Padang.

Rahman,Lina.(2010). "A study on second language speaking anxiety among UTM students". Malaysia : Universiti Teknologi Malaysia.Unpublished paper Shoelhi,Mohammad.(2015)."Komunikasi lintas budaya dalam dinamika komunikasi internasional". Bandung:: PT Remaja Rosdakarya 